\title{
Bus Semirapid Transit Mode Development and Evaluation
}

\author{
Vukan R. Vuchic \\ University of Pennsylvania
}

\begin{abstract}
With little investment required for operating in streets, bus services are often designed to serve many overlapping routes with frequent stops. To upgrade services and attract choice riders, major bus routes should be provided with exclusive lanes, preferential signals, and fewer but more distinct stops.

The Federal Transit Administration's (FTA) Bus Rapid Transit (BRT) program is aimed at upgrading bus services into semirapid transit category (technically, bus semirapid transit). Many similar programs in the past were initially successful but later degraded by allowing sharing of lanes by high-occupancy vehicles (HOV) and relaxed enforcement of traffic control. With the systems approach organized for the BRT program, implementation chances will be greatly enhanced. It is expected that a successful BRT program will have a positive impact on many other bus services. Improved bus services should be seen as a significant step to higher-quality, attractive transit services which will represent major lines in smaller cities or complementary lines with rail transit in larger ones.
\end{abstract}

\section{Introduction}

The vast majority of bus services consist of buses running in mixed traffic on many overlapping lines with different headways. In many cities the obsolete practice of having bus stops on every corner is still used. Bus travel speed is often low, and reliability depends on traffic conditions. With complex line alignments 
and confusing networks, buses often can not compete with car travel, so they serve mostly captive riders.

Upgraded bus services, primarily those with separate rights-of-way, represent a very cost-effective method to increase transit usage. Many measures for bus service improvements were introduced since 1970 (Wilbur Smith and Associates 1975; OECD 1977; RATP 1977), but in many cases buses were gradually returned to operations in mixed traffic. The present FTA program promoting BRT (Transportation Research Board 2001; Diaz and Schneck 2000) is a logical step forward in improving not only bus transit but the quality and image of transit services in general. As introduction of new light rail transit (LRT) systems improves transit image in the entire city, introduction of a BRT line should be expected to have a beneficial impact on other bus lines, as well as on intermodal integration between bus and rail transit lines.

The designation BRT is actually a trademark of the federal program. Technically, with partially separated rights-of-way, this mode belongs in the semirapid transit category. This article discusses bus semirapid transit (BST) and compares it to neighboring modes: regular bus (RB) and LRT.

\section{Definition and Characteristics of Transit Modes}

The selection of transit mode is a critical decision in planning new transit systems. To perform this complex task correctly, it is necessary to precisely define transit modes and their components and to have a thorough knowledge of characteristics and relationships of different modes. Moreover, it is necessary to avoid simplistic evaluations based on a single criterion, such as minimum cost.

Three main characteristics define transit modes: right-of-way (ROW), technology, and type of operations. Although vehicle technology is most visible and the public tends to recognize the modes as bus, trolleybus, light rail, and metro, the ROW category is actually the most important mode feature. It determines the basic characteristics of modes and strongly influences the selection of system technology, vehicle design, and operational features.

The basic characteristic of ROW is its degree of separation from other traffic. In this respect, three categories of ROW are defined, and they determine generic modes of urban transit. 
1. ROW category $\mathrm{C}$ represents urban streets with mixed traffic. Transit vehicles, bus or rail, operate in mixed traffic. Modes utilizing ROW category $\mathrm{C}$ represent street transit, which requires very low investment (streets already exist) but operates with speed, comfort, and reliability of service that depend on traffic conditions, so that they may be variable.

2. ROW category B is partially separated from other traffic but has crossings at grade. Typically, this ROW is a curbed street median with LRT tracks, which go through intersections and can be crossed by pedestrians. LRT tracks may also go through parks, on railway ROW, etc. Physically separated (curbed) bus roadways also represent category B. Modes with this type of ROW are called "semirapid transit." They require substantially higher investment than street transit but also provide higher performance.

3. ROW category A is fully controlled and used exclusively by transit vehicles. Representing rapid transit generic class, these transit systems require the highest investment, but they also provide by far the highest performance in terms of speed, reliability, capacity, and safety.

Figure 1 is a diagram of mode performance versus investment costs per kilometer of line for three categories of transit modes, representing, respectively, street, semirapid, and rapid transit. This diagram shows that street transit modes, such as regular bus, involve the lowest investment cost but have the lowest performance. Semirapid and rapid transit require considerably higher investments but provide higher performance.

The entire family of transit modes is listed in Table 1, starting from the basic one, bus operating on streets, to modes which have more advanced featuresfrom ROW category $\mathrm{C}$ to $\mathrm{B}$ and $\mathrm{A}$, from diesel internal combustion engines (ICE) to electric motors, from steered single vehicles to guided long trains. As these features change, modes have higher performance in terms of speed, reliability, capacity, safety, and image. This sequence shows that the ROW category is the basic element which determines the mode technology and thus influences features of modes and their performance. For example, once ROW category A is selected and major investment has been made, it is logical to fully utilize it by 
Journal of Public Transportation, Vol.5, No. 2, 2002

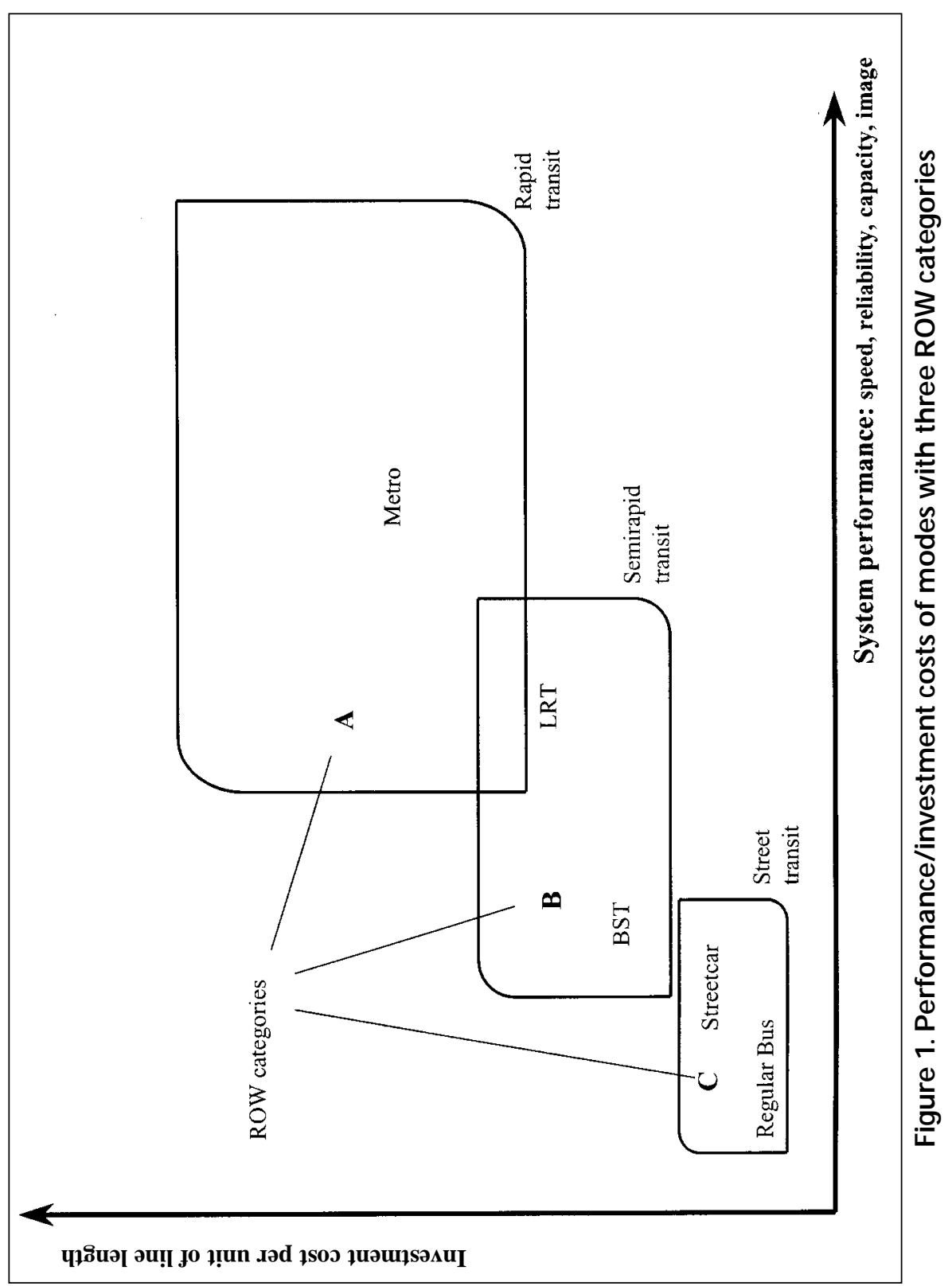




\begin{tabular}{|c|c|c|c|c|c|c|}
\hline 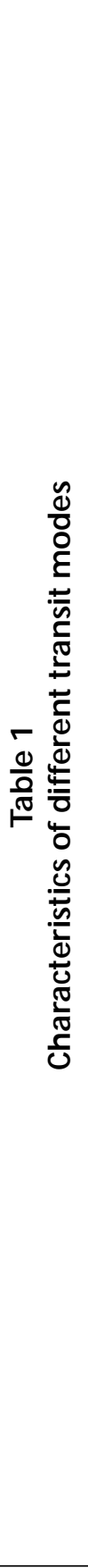 & 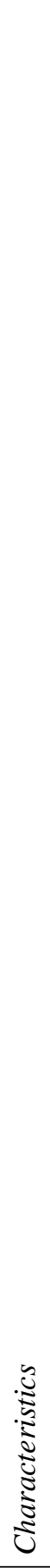 & 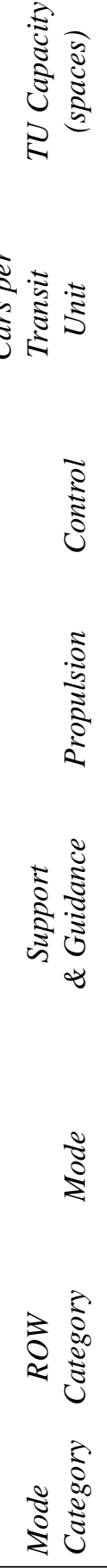 & 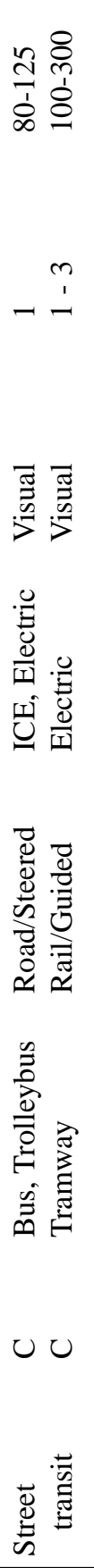 & 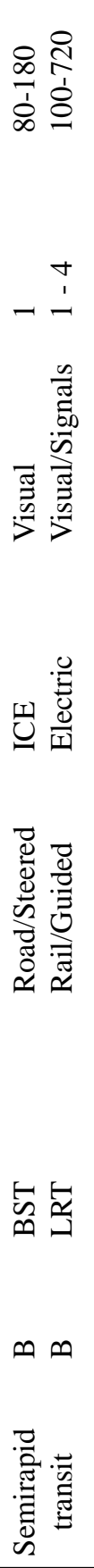 & 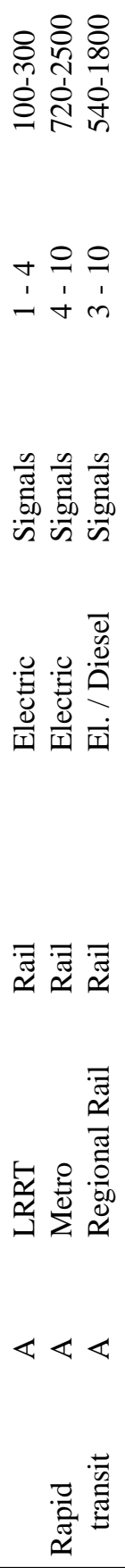 & 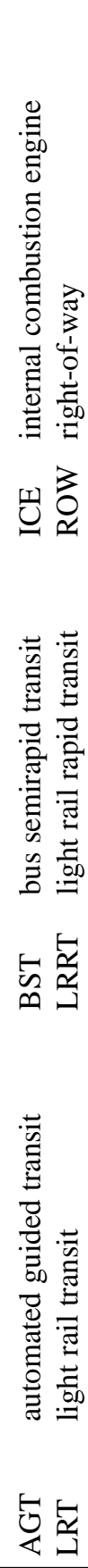 \\
\hline
\end{tabular}


introducing advanced modes, such as those with electric traction, large vehicles, and trains. They allow full utilization of the high-investment ROW category A.

These definitions show that improved buses with separate lanes, as well as LRT, represent semirapid transit, rather than rapid transit. The BRT designation is a popular "sales" name, but the technically correct name is bus semirapid transit.

\section{Correcting the Misconceptions about Transit Systems from the 1950- 1970 Era}

During the era of most intensive increase in auto ownership and construction of urban highways, 1950-1970, transit was neglected and features of different modes and their roles in urban transportation were often misunderstood. Some of the misconceptions about transit modes and services from that period have presented serious obstacles in planning transit systems. It is, therefore, useful to critically review some fundamental misconceptions about transit that were dominant and caused many erroneous decisions several decades ago. Four major misconceptions are discussed below.

\section{Misconception I:}

Transfers Are Not Tolerable: If Passengers Must Transfer, Choice Riders Will Not Use Transit.

This belief has resulted in attempts to provide more door-to-door services by running large numbers of complicated bus routes with very low service frequency, poor image, and low passenger attraction.

\section{Fact l:}

Intermodal, high-quality transit networks require transferring.

With good design, passengers easily accept transfers. The best transit systems (New York, Toronto, Munich, Paris) involve extensive transferring among lines and modes.

\section{Misconception II:}

Transit Can Be Provided Either by Buses on Streets, or by Rail Rapid Transit.

This planning misconception created bipolarized systems that have services represented by the diagram in Figure 1 with only street and rapid transit. It left many cities unsuited for rapid transit without any options for transit upgrading. 


\section{Fact II:}

Many lines and networks need better service than buses on streets can offer, but for much lower investment than metros require.

This need has resulted in the development of LRT and BST in recent decades; these modes have filled the gap between street transit and rapid transit (Figure 1).

\section{Misconception III:}

Bus Lines Must Have Stops at Every Corner, While Rapid Transit Must Compete with the Car, Relies on Park-and-Ride, and Needs Few Stations. This is an extreme polarization of modes by type of operation. Buses sacrifice speed for easy access: stopping at every corner creates slow, creeping bus services. Rapid transit, on the contrary, sacrifices access for high operating speed among few stations. With long station spacings, some metros designed in the 1960s do not serve many areas along their lines and discourage walk, bicycle, and transit feeders. The former loses choice riders because it is very slow and unreliable; the latter loses potential riders because it bypasses them, resulting in poor area coverage.

\section{Fact III:}

This bipolarization in access/speed ratios needs correction: fewer stops for buses, more stations for rapid transit.

\section{Misconception IV:}

Flexible Transit Systems and Services are Needed.

The vague term flexibility has been falsely proclaimed to be always a major goal in transit planning. It has been used not only to criticize transit systems, particularly rail, as "inflexible," but also to imply that transit services which are changeable in alignment and schedules are superior to the fixed, permanent, reliable ones.

\section{Fact IV:}

Concepts opposite to flexibility are: permanence, reliability, durability, efficiency, simplicity. These are desirable features for most transit services (Vuchic 1971).

Thus, while some transit services, such as commuter lines, can be diversified in scheduling and dispersed in routing, most transit services aimed 
at attracting incidental users and the general public must have fixed routes, fixed schedules, and known fares. They must be simple to understand and use. Moreover, the more fixed they are, the more they have strong impacts on land uses, as well as on quality of life in the city.

Attempts to create a higher performance bus system (e.g., BST) are aimed at giving it the feature of fixed, permanent, rather than flexible service (see Figure 2). Initially, a large number of bus routes converge on a trunk line, offering complicated, irregular service. In many cases these services are improved if the trunk is upgraded into an independent rail or BST line. Despite transfers, service on separate ROWs, attractive stations, and regular headways by one or a few rather than by many lines attract more riders. Figure 3 shows such an upgrading made in Sacramento when semirapid transit (i.e., LRT) was introduced on the trunk line, replacing many bus lines. Major ridership increases were achieved.

\section{Family of Transit Modes and Balanced Transportation System}

Experience from cities around the world has reaffirmed in recent decades the fact that there is a need for a "family of transit modes," ranging from regular buses on streets to rail rapid transit (metro) and regional rail systems. Each major mode has a domain of applications in which it is more efficient than other modes. The neighboring modes, such as bus and trolleybus or LRT and metro, have certain overlaps in their domains.

In large cities, a single transit mode cannot provide as efficient service as several coordinated modes. The need for intermodal systems has now been recognized not only by transportation professionals but also even by laws: "Intermodal" is the concept incorporated in the title of the Federal Transportation Act of 1991, ISTEA. An intermodal system in which each mode has a role in which it is most efficient is defined as a "balanced urban transportation system" (Vuchic 1999, p. 235). "Efficiency" is used here as a comprehensive concept, including the quality of service for passengers and operating efficiency which the transit agency experiences. Moreover, the long-term impact a mode can have on the city may in some cases be a major aspect of its efficiency. 


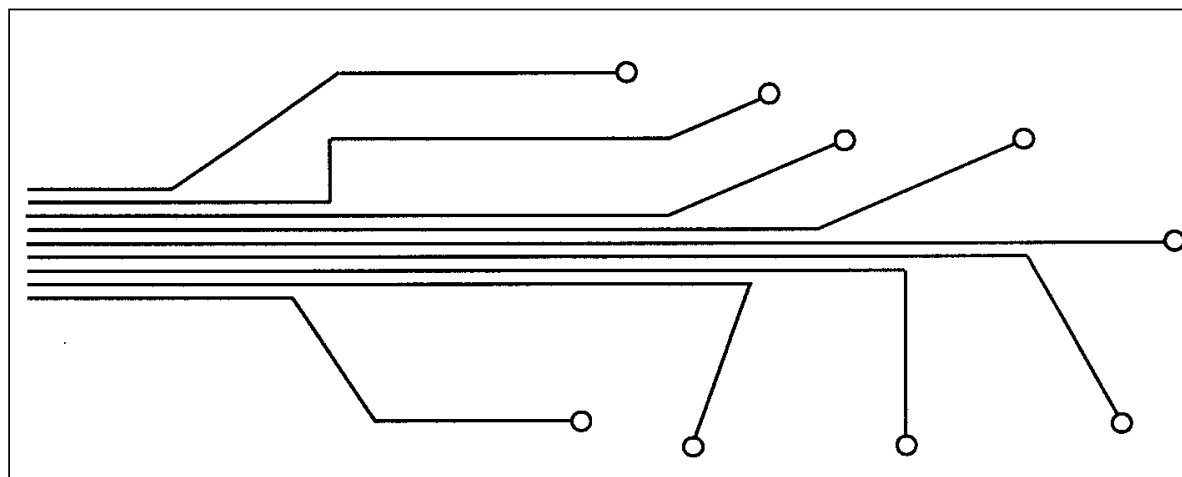

a. Trunk line with branches

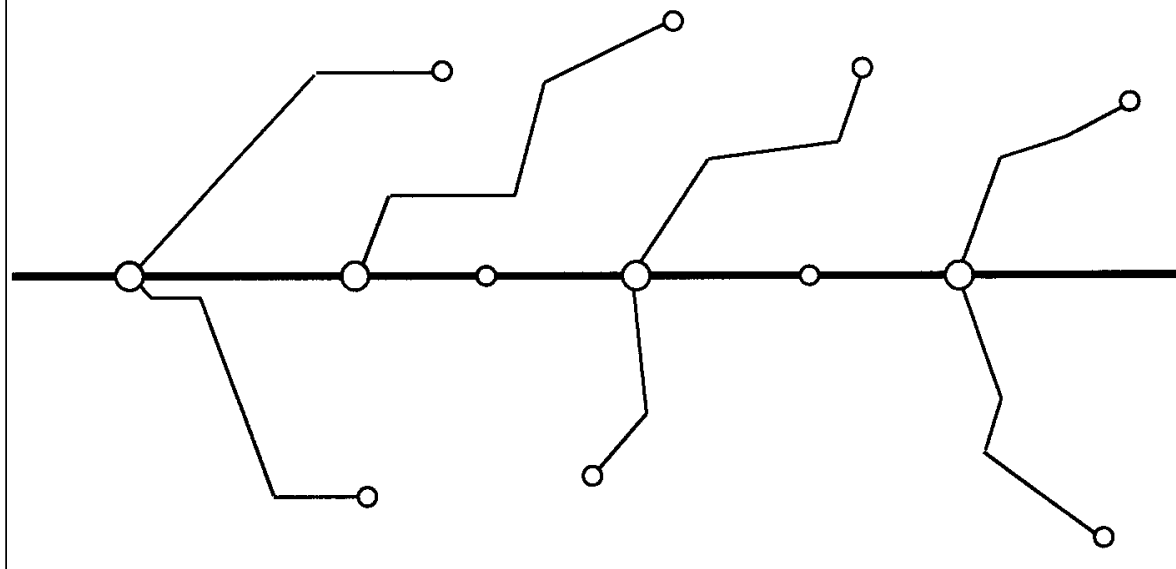

b. Trunk line with feeders

Figure 2. Radial transit trunk line with branches (a) and with feeders (b) 


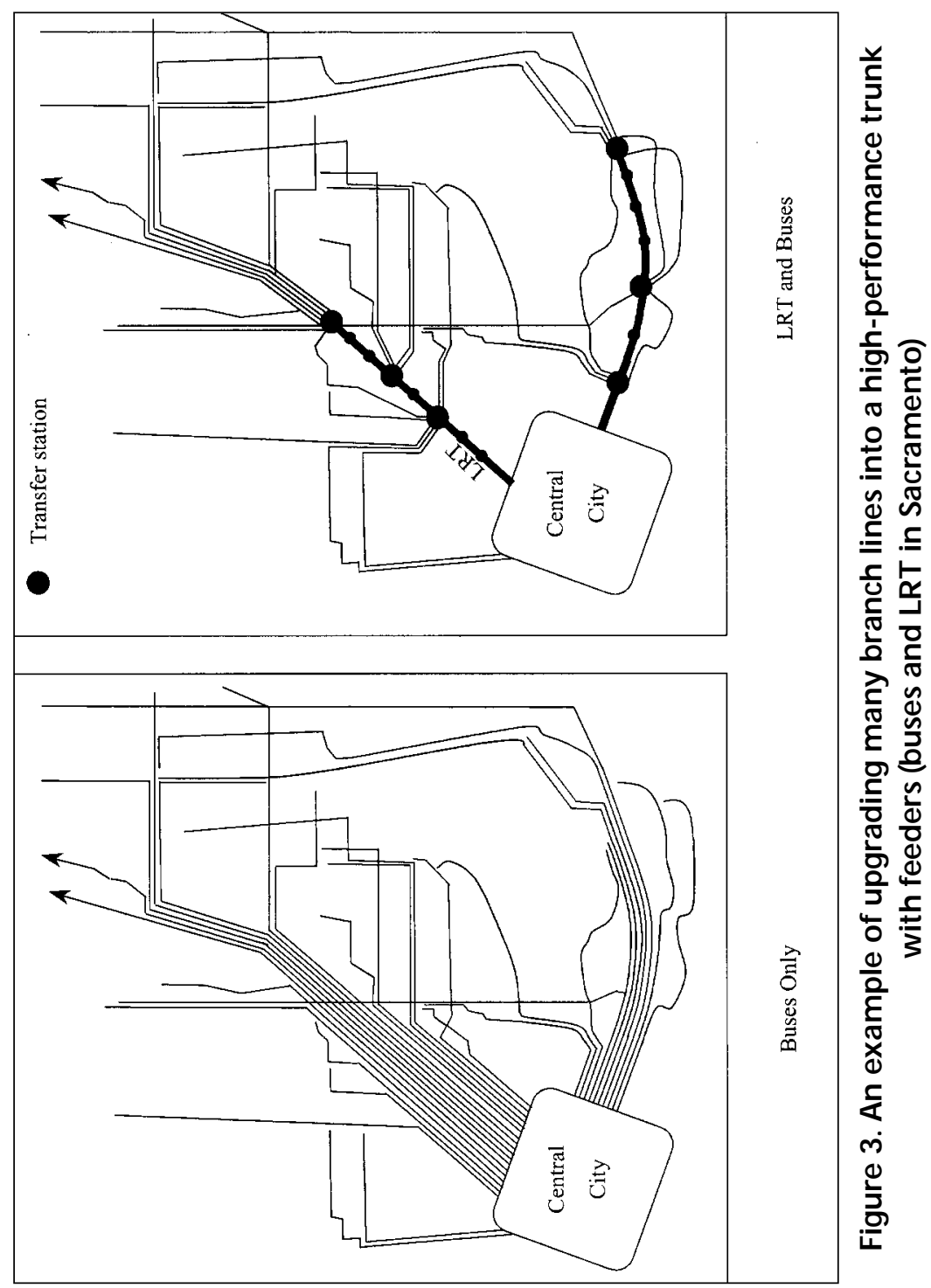


The need for utilization of the family of transit modes has been the reason for strong development of semirapid transit modes. The strongest representative of these modes is LRT, which has been built in dozens of world cities since the mid-1970s. In North America alone, new LRT systems have been built in about 20 cities, and their development is continuing at a strong pace. Now the development is also focusing on BST, "junior" partner of LRT in the semirapid transit category, as shown in Figure 1.

\section{Emergence of BST as a Concept}

The concept of improved buses, mostly by upgrading their ROW to category B, has been implemented in different forms since about 1970 (Peat Marwick Mitchell \& Co. 1970). Many events that have occurred in this development deserve careful attention because they indicate which innovations can be efficiently introduced and which ones face many obstacles. Major developments are briefly presented and analyzed here, designated as advancements (+), various experiences $(\sim)$, and setbacks $(-)$.

+ Introduction of BST as a system concept (Wilbur Smith and Associates 1975; Verband Öffentlicher Verkehrsbetriebe \& VDA 1979; Vuchic 1981; Vuchic and Kikuchi 1994) has led to the recognition of the following main factors needed to upgrade conventional, regular bus services into BST:

- $\quad$ separate lanes (ROW B), priority treatment at signalized intersections, stop spacings of 300 to $500 \mathrm{~m}$, and usually vehicles designed for specific operating conditions;

- few fixed lines with frequent service (instead of many infrequent "flexible" ones);

- $\quad$ easy and convenient transfers among lines and modes; and

- $\quad$ separate infrastructure and distinct bus designs that provide a much stronger image than regular buses have.

+ Exclusive bus lanes and busways were built already during the 1970s in a number of cities. The best known successful busways were built in Ottawa, Pittsburgh, the Washington, D.C. (Shirley), Los Angeles (El 
Monte), São Paulo (Comonor), Lima, and Mexico City (Ejes Viales). They were followed by the busways in Curitiba, in Adelaide, in several French and British cities, and O-Bahn in Adelainde.

The commuter busways concept was adopted in several U.S. cities instead of busways for regular BST systems. The extensive systems of busways in Houston, Seattle, Washington-Shirley HOV facility, and many others are unidirectional roadways which provide efficient commuter services to and from downtown, but they do not represent regular, all-day transit systems which constitute an integrated network.

- The concept of HOV lanes or roads was introduced in the United States during the late 1970s. It led to the conversion of most busways into HOV facilities. This change did improve utilization of facilities in terms of vehicles, but it benefited carpools and vanpools, while bus users experienced a distinct degradation of service and image of BST. Moreover, the new phenomenon of "ad hoc carpooling," performed at the ramps of former busways, resulted in direct "stealing" of transit passengers. The decrease in transit ridership eventually resulted in reduction of bus services. Today, most cities allow all vehicles with two, three, or more persons to mix with buses in the former exclusive busways. Thus, in the United States, busways have virtually disappeared, with the exception of Pittsburgh and very few other cities, where they are owned by the transit agencies.

- Bus lanes on streets have faced a similar problem to busways. Pressure always develops to let other vehicles, such as taxis, HOVs, and trucks into bus lanes. In recent years in the United States, even HOV facilities on freeways are under attack by single-occupancy vehicle (SOV) motorists who see free-flowing lanes next to the congested lanes in which they are traveling.

+ Bus vehicle design has had very significant advances. These advances include new vehicle types such as "push" articulated bus, double-articulated bus, and low-floor bus. In addition, many buses now offer increased comfort, large windows, improved appearance, and cleaner engines (Hondius 1975). 
$\sim$ Progress with priority treatments at intersections has been very slow. Although the technology for signal and other priorities has existed for decades (Vuchic 1981), even today in Boston, Baltimore, and Los Angeles buses with 80 persons and LRT trains with 300 to 400 persons are treated at intersections with the same rights as cars with an average of 1.3 persons. Priorities for buses are operationally and politically even more difficult to implement than for rail systems, because of their full technological compatibility with street traffic. For example, bus priorities at signalized intersections along South Busway in Miami have been suspended due to several accidents.

- Many bus priority measures have been diluted or eliminated due to inadequate police enforcement, as well as political pressures (Philadelphia, Chicago, Mexico). The bus lanes on Santa Monica Freeway, evaluated positively by detailed professional studies, were eliminated in the 1970s by a legal action (i.e., by a judge who was a complete layperson with respect to urban transportation). City council members sometimes force elimination of transit priorities or enforcement of parking regulations.

$\sim$ Interactions with surroundings and impacts on the served areas have varied. Good coordination between transportation and land-use planning in Curitiba (Rubinovitch and Leitman 1996) and Ottawa enabled BST systems to have positive impacts on land development around major stations and along the served corridors. In São Paulo, on the other hand, corridors along the highest capacity bus/trolleybus lines have deteriorated economically and environmentally due to the intensive noise, pollution, and separation of the two sides of the avenue. The lines suffer from rather poor image problems.

$\sim$ O-Bahn or guided bus has had unfulfilled expectations with respect to implementation (Vuchic 1985). The Adelaide system has remained the only major facility with guided buses. Even in the Seattle bus tunnel, where such a system had potential, guided buses were not introduced.

+ Applications of Intelligent Transportation Systems (ITS) for upgrading bus services have already been significant, and there is considerable potential for their wider use in BST operations, passenger information, and safety. 
- Deregulation of bus transit, such as in Great Britain, has resulted in breaking up bus systems and making their technical and organizational upgrading much more difficult. For example, a very effective busway in Lima, Peru, was discontinued when deregulation was introduced. In Mexico City replacement of most bus services by deregulated minibuses has practically destroyed reserved bus lanes and other BST features that had been introduced with very positive results.

This review of the historic development of the BST concept and elements since the 1970s shows that many efforts to upgrade buses have been made. Some represent significant progress, while others met difficulties and were partially successful, or even represented setbacks. Major experiences from these developments and lessons for the future can be summed as follows:

1. Bus services are upgraded when extensive but infrequent, "flexible" bus lines are replaced by fixed routes with separate lanes, fewer but more distinct stations, and frequent service.

2. The main obstacles to upgrading bus services have been organizational and political, rather than technological.

3. Provision of separate bus lanes and roadways must be followed by their continuous protection from pressures by lobbies to share these facilities with car, taxi, truck, and other vehicle categories.

4. Most steps of bus upgrading, such as provision of separate ROW, stations, distinct trunk service with transfers from feeders, and stronger image, make bus lines more similar to LRT.

5. Successful BST systems are found in cities which have very strong planning, good traffic engineering, and a clear policy of prioritizing modes on the basis of the number of persons they carry. Ottawa and Curitiba illustrate the importance of these conditions.

\section{Analytical Comparison of RB, BST, and LRT Modes}

The "family of transit modes" shown in Figure 1 grouped the modes into three categories and located BST between RB and LRT. Therefore, in evaluating transit alternatives for upgrading transit systems, the comparison of these three modes is very common. A visual presentation of their physical, technical, and 


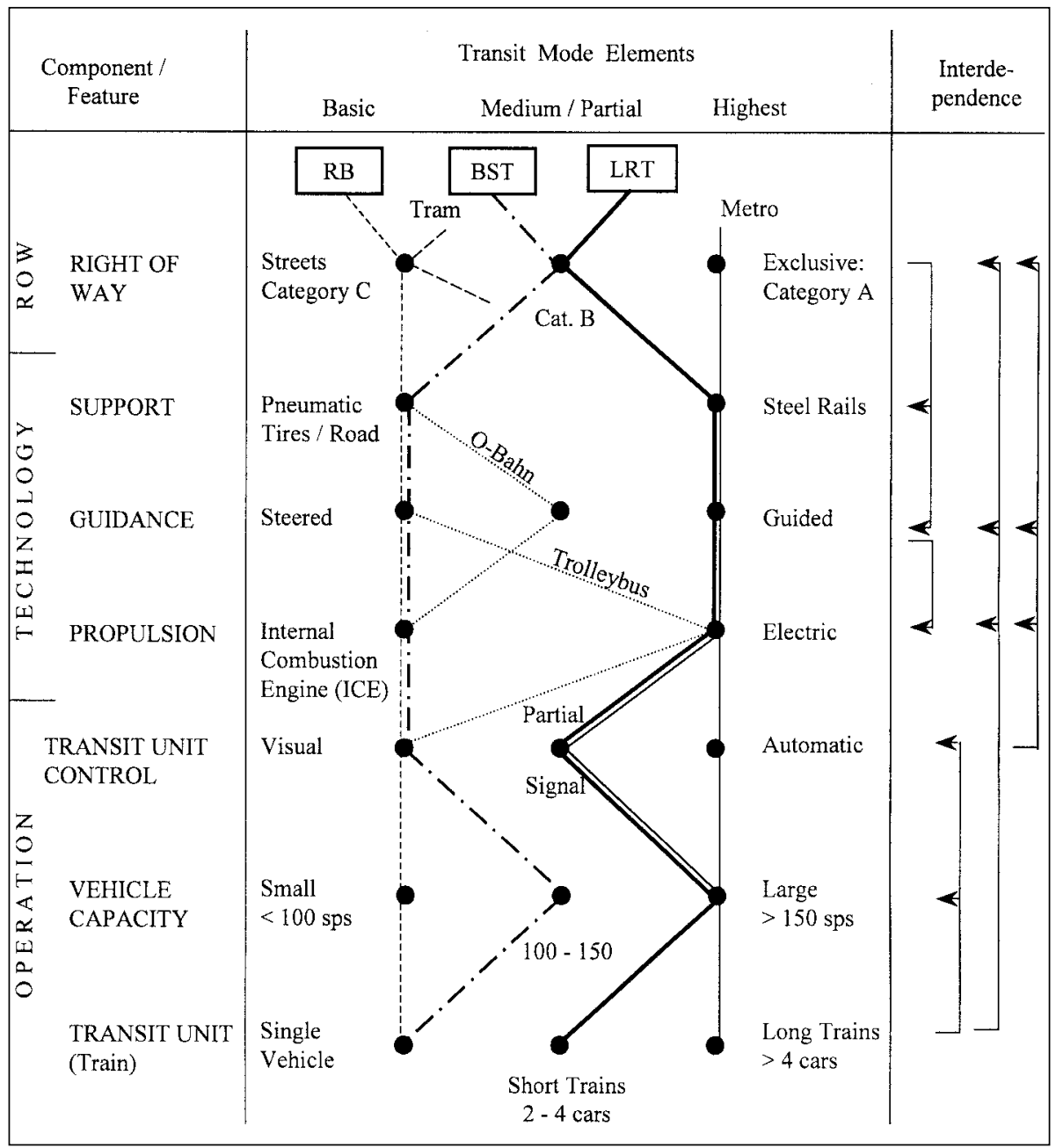

Figure 4. Graphic presentation of the physical and technological features of different transit modes 
operational characteristics is given in Figure 4. This diagram is set up so that any mode of urban transportation, be it trolleybus, bus, metro, or automated guided transit, can be shown on it by a line connecting its respective components. The first section shows the most important physical component-ROW category, followed by the sections with components of technology and operation. On the left are the base-level components: single, road vehicles, steered and controlled by the driver and powered by ICE. On the right are advanced features: guided technology, electric propulsion, signal control, high-capacity trains, and others.

The lines with arrows in the last column show interdependence of features. For example, automatic operation requires electric traction, guided technology, and exclusive ROW, category A.

The basic transit system, RB, which is most economical and efficient for lowvolume lines, has the components on the left side of the diagram. The highest-performance transit mode, metro with full automation, which is optimal for high-volume lines, is represented by a straight line on the right side. The lines representing RB, BST, and LRT clearly show the differences among these three modes.

BST has the same technology and driver-steered single vehicle operation as RB but different ROW category. LRT has the same ROW category as BST, but it has higher-performance technology features: guidance which makes possible use of larger vehicles and trains of up to four cars, electric propulsion, and partial signal control (used on high-speed or tunnel sections). Most other differences between these modes result from the two differences: change from ROW $\mathrm{C}$ on RB to ROW B on BST and LRT, and change from diesel road vehicles on bus systems to electric rail vehicles on LRT systems.

Table 2 presents components and characteristics of the three analyzed modes, RB, BST, and LRT. They are classified into three groups: system components, lines/operational elements, and overall system characteristics. Major features will be briefly discussed. (These are generalized mode characteristics, not necessarily precisely valid for each specific transit system.)

\section{System Components}

The first group, system components, summarizes the modal features from Figure 4. With respect to elements of lines and operations, typical BST systems 


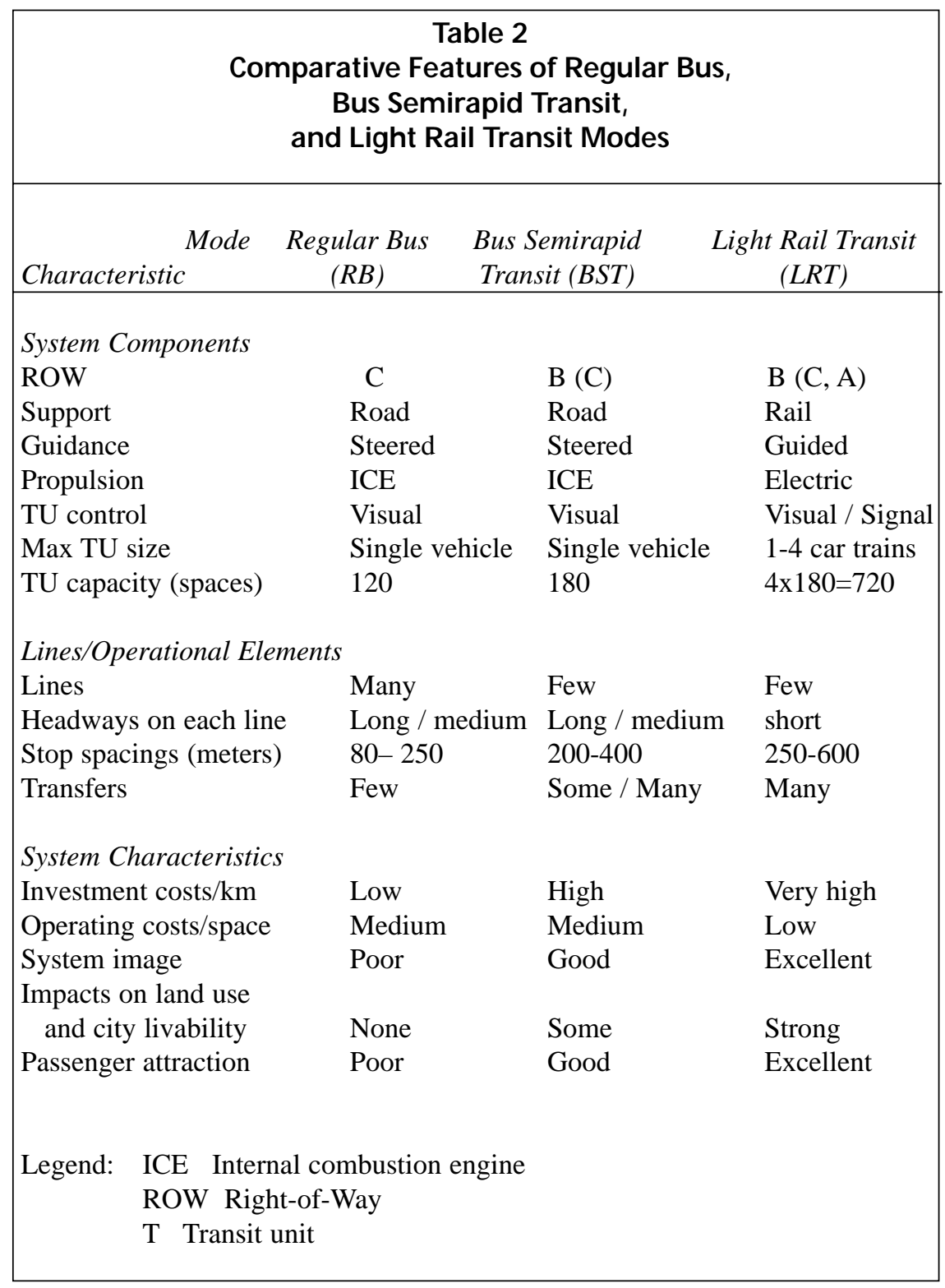


have lines that are more intensive than those of $\mathrm{RB}$, but still more extensive (more branches) than LRT. Bus lines and their networks have more stops, lower speed, and usually longer headways than rail lines. When an LRT line is built, the network is changed from an extensive to intensive one, with trunk and feeders, as shown in Figures 2 and 3. While intensive LRT lines involve more transfers, they are organized so that transferring is made conveniently. Usually the advantages of intensive lines with respect to frequency, reliability, and comfort are such that they more than outweigh the disadvantage of transferring.

\section{Lines/Operational Elements}

BST demonstrates that bus lines do not have to form extensive, confusing networks with long headways, which are intended to minimize transfers. Actually, in many ways, the more buses adopt operational features typical for rail lines, the more passengers they attract. This is clear from the fact that the most successful BST systems, such as in Ottawa, Curitiba, and the planned BRT systems in several U.S. cities, are created by changing them from extensive networks with many lines and close stops to major trunk lines with ROW category B, large (articulated) vehicles, longer station spacings, and transfers to feeder bus lines.

A good example of these system design and operational features are the recently introduced Metrorapid lines in Los Angeles. They represent former RB lines upgraded by several BST/LRT elements, such as stop spacings increased from 250 to $600-800 \mathrm{~m}$; priority signals at intersections; high-quality buses with distinctive red coloring; strong image of lines with a special name "Metrorapid." The result of these upgrading elements has been a significant increase of passengers.

\section{System Characteristics}

System characteristics, given in the third section of Table 2, result from system components and line elements. Physical characteristics of the bus and rail modes account for fundamental differences between the first two and the third system. Investment cost, which is very low for $\mathrm{RB}$, is much higher for construction of separate BST facilities, and then even higher for electrified LRT. System image and passenger attraction improve with upgrading to BST, and even more so with LRT. Finally, impacts on land-use development along the line are generally related to the permanence and image of transit system facilities. In that respect, again $\mathrm{RB}$, consisting mostly of buses on streets which can be relocated 
at any time, has no impact. BST may have an impact if planning is energetically pursued, but LRT has a distinct advantage due to the greater permanence and physical presence of rails and separated ROW.

Focusing now on the two semirapid transit modes, BST and LRT, their main features can be compared in a summarized manner as follows, covering the service the passengers experience, system costs, and impacts/interactions with the served areas.

- Vehicle performance and passenger comfort: Due to electric propulsion and more spacious, stable rail vehicles, LRT has a distinct advantage.

- Investment cost: BST has a significant advantage in this respect over LRT. Exceptions may be in physically constrained areas and in construction of stations which must be greater to accommodate overtakings of buses.

Buses are also considerably cheaper than LRT vehicles, although the difference in their life cost is not as great as the difference in their purchase prices because rail vehicles have 2.5 to 3 times longer lifespans (buses last 10-15 years, LRT vehicles 25-40 years). Correct comparison must be based on lifecycle cost per unit of vehicle capacity.

- Implementation time: BST again has an advantage because it does not require any new technology and special installations, such as electric power supply, or signal system.

- Operating cost: This varies with passenger volume. Generally, operating costs are lower for buses with low-to-moderate volumes, but lower for rail when large volumes are carried, due to economies of scale of large vehicles and train operation.

- System image and passenger attraction: BST has a stronger image than $\mathrm{RB}$, while rail tracks make LRT lines even more distinct and permanent, giving this mode a significantly stronger image than any bus lines can have. 
Passenger attraction of the two modes is often discussed. Evidence from many cities shows that on a given general alignment LRT attracts considerably more passengers than BST. Examples are the substantiated ridership increases when LRT replaced buses in a number of cities, such as Calgary, St. Louis, Denver, and Dallas.

On the theoretical side, models relate passenger attraction to the parameters of transit service. If the models are developed correctly, they must reflect not only the speed and frequency of service, but also vehicle comfort, line simplicity, image, and attraction in which BST ranks between RB and LRT.

- Environmental impacts (air pollution and noise): There has been considerable progress in the development of less polluting ICEs, such as "clean diesel" and CNG engines. However, buses still produce exhaust which is objectionable, particularly in areas with high concentrations of people. It also prevents bus use in tunnels. Noise produced by buses remains a problem. For example, intensive BST corridors in São Paulo are strongly criticized for the exhaust and noise they produce along the lines.

Trolleybuses produce no gases, and they represent the quietest transit vehicle. BST systems in Quito and some in São Paulo use trolleybuses.

LRT produces no air pollution, and its noise is extremely low. This makes LRT more desirable for to center city streets and pedestrian areas than BST.

- Interaction with land development: As already discussed, LRT has a considerably greater potential to influence development of land in its service areas than BST.

Comparisons between BST and LRT are summarized in Table 3. Because bus technology requires lower investment and it is easier to implement on the lines where low or moderate capacity is needed, BST is the superior mode. LRT is generally superior for serving major transit corridors, as well as for lines which go through pedestrian areas, penetrate into urban developments for, or must use tunnels. Thus, BST is the logical solution where RB lines need upgrading through introduction of bus lanes and priority treatments, while LRT generally dominates the higher range of the semirapid transit applications. 


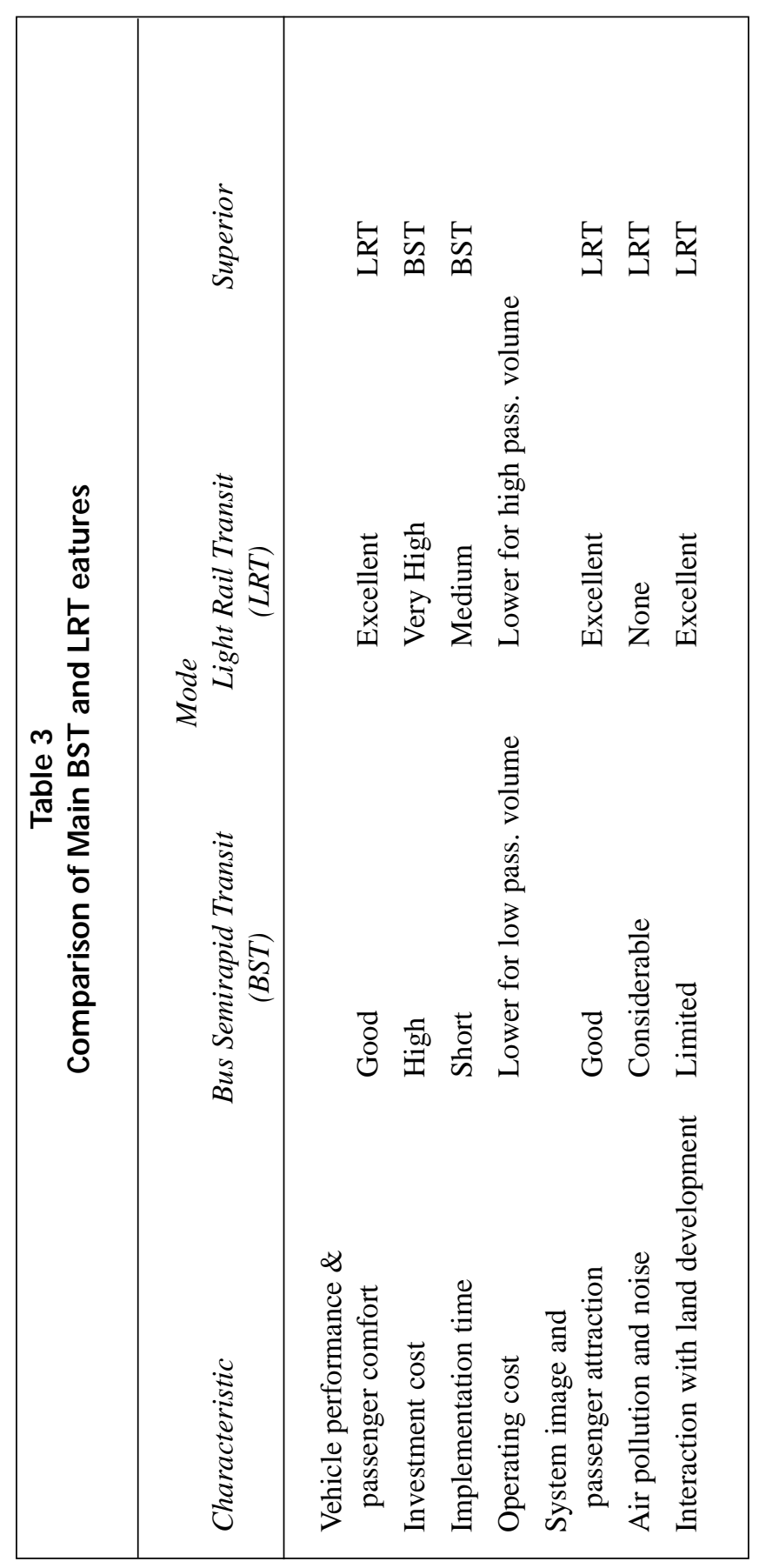


Alignments which require expensive ROW construction (valleys, constrained areas, hilly terrain, rivers, and lakes which require bridges and tunnels) are better suited to LRT because of its higher capacity. Moreover, the additional investment in rails and electrification is well worth the superior system performance which LRT offers. In other words, if a large investment is made in ROW construction, it is usually logical to make the additional investment that would greatly improve system performance and image.

Which one of the two modes is selected for a specific case in the "middle range," depends not only on the passenger volumes, types of lines, and estimated costs, but also on the last three items in Table 3: system image and ability to attract passengers, environmental compatibility in the served areas, and impacts on land development and quality of life. These aspects are difficult to quantify, but they may have a great significance for mode selection in many cases, because they influence the role of transit and thus the character of the city (see also Vuchic and Stanger 1973; Vuchic 2000).

Evaluation of various system aspects in selecting modes from performance, capacity, and costs to the role transit should have in the served areas depends greatly on local attitudes. In some cases transit service is considered mainly with respect to its transportation function; BST can be implemented sooner than LRT and satisfy that requirement. In others, the visual and symbolic aspects of rail transit, its sense of permanence, and positive impacts on urban character may also be given considerable importance. Such situations would favor LRT.

\section{Conclusions: Prospects, Problems, and Future Role of BST}

The prospects for implementation of BST systems are very good because there is a need for improvement of bus services in numerous corridors of many cities. Actually, potential benefits from the BST promotional program is considerably greater than implementation of several systems that can be designated as BST. Many individual elements and operational concepts of BST can be applied to regular bus services in most cities. The significance of BST is also great because it highlights the following facts:

- Bus services should be planned and operated as systems, rather than as a set of buses placed in service on certain alignments. Their ROW, stops, vehicles, and operations must be integrated in efficient transit systems. 
- Many bus services can be upgraded from the present, usually slow, stopping-at-every-corner transit service for captive riders to an attractive mode of urban transportation.

- Transit vehicles, including bus and LRT, should be given preferential treatment at intersections over general traffic on the basis of their much higher number of passengers as well as their public service role.

- Reserved transit lanes should be limited to transit vehicles only. Sharing the lanes with other vehicle categories, reserving them for certain periods of time only, and reverse directional use, are sometimes good temporary solutions, but they dilute the image and decrease efficiency of transit services.

Despite the potential for BST implementation, there are serious obstacles to it. As discussed above, many attempts to implement various components of the BST mode have met with considerable resistance and obstacles. Obtaining exclusive bus lanes and preferential treatments, maintaining them, defending them from pressures to allow HOVs and other vehicle categories, are experienced in most cities. Planners of BST systems must be aware of these problems, anticipate them, and prepare how to overcome them.

Most likely conditions for successful application of BST may be defined as follows:

- corridors with many overlapping bus lines;

- streets and avenues where separate bus lanes can be introduced; and

- political and civic support for transit in traffic regulations are sufficiently strong that bus priority measures can be introduced and maintained.

In conclusion, the potential role for BST is to influence upgrading of major bus services and provide the first-level semirapid transit. It should be considered as complementary to or a stage of development toward LRT or a metro system. 


\section{References}

Diaz, R. B. and D. C. Schneck. 2000, Bus Rapid Transit Technology in the Americas. Washington, DC: TR Record 1731, pp. 3-9.

Hondius, H. 1995. State of the art of bus, hybrid bus, trolleybus and intermediate systems. Public Transport International \#6, pp. 24-31. Brussels: UITP.

OECD Road Research Group. 1977. Bus Lanes and Busway Systems. Paris: OECD.

Peat Marwick Mitchell \& Co. 1970. A Case for Bus Transit in Urban Areas.

Rabinovitch, J., and J. Leitman. 1996. Urban planning in Curitiba. Scientific America. March, pp. 26-33.

RATP. 1977. Autobus en Site Propre (Bus on Separate ROW). Paris.

Transportation Research Board. 2001. BRT-Bus Rapid Transit. Washington, DC.

Verband Öffentlicher Verkehrsbetriebe and VDA. 1979. BusVerkehrssystem. Dusseldorf: Alba Buchverlag.

Vuchic, V. R. 1971. The concept of flexibility in transit system analysis. High-Speed Ground Transportation Journal 5:53-61.

Vuchic, V. R. 1981. Urban public transportation systems and technology. Englewood Cliffs, NJ: Prentice-Hall.

Vuchic, V. R. 1999. Transportation for livable cities. New Brunswick, NJ: Rutgers University Center for Urban Policy Research.

Vuchic, V. R., and S. Kikuchi. 1994. The bus transit system: Its underutilized potential. Report DOT-T-94-20 to Federal Transit Administration. Washington, DC: U.S. Department of Transportation.

Vuchic, V. R., and R. M. S. Stanger. 1973. Lindenwold Rail Line and Shirley Busway B. a Comparison. HR Record 459, pp. 13-28. Washington, DC.

Vuchic, V. R. 1985. O-Bahn B description and evaluation of a new concept. TR Record 1011, pp. 8-15 Washington, DC.

Vuchic, V. R. 2000. Comparison of light rail transit with bus semirapid transit. 5th UITP Light Rail Conference, Melbourne. Brussels: UITP.

Wilbur Smith and Associates. 1975. Bus use of highways. NCHRP Report 155. 


\section{About the Author}

VuKan R. VuCHIC (vuchic.seas.upenn.edu) is UPS Foundation Professor of Transportation in the Department of Systems Engineering at the University of Pennsylvania. He has lectured at about 70 universities and authored about 140 reports, book sections, and articles published in the United States and foreign countries, mostly on various aspects of urban transportation. His book Urban Public Transportation Systems and Technology (Prentice-Hall 1981) contains descriptions, analyses, and design aspects of bus, rail, and other transit modes.

One of Dr. Vuchic's specialties has been evaluation and comparative analysis of different transit modes, such as bus, semirapid bus, light rail, rapid transit, and regional rail. Dr. Vuchic wrote the first report defining light rail transit in 1973, which contributed to the introduction of LRT to North America. He also wrote a report in 1994 supporting strong upgrading of bus services which was followed by FTA's current strong promotion of "bus rapid transit." 